\title{
'It's been a massive struggle': Exploring the experiences of young people leaving care during COVID-19
}

\section{Introduction}

Transitions to adulthood take place from different starting points and with differential access to available resources. Young people leaving care are often disadvantaged in these transitions, which have been characterised as both 'accelerated and compressed' (Stein 2008: 400). Care experienced young people also need to negotiate inequalities in terms of education, employment, and housing (Allnatt, 2019; Artamonovaa et al, 2020; Brady and Gilligan, 2019; Girling, 2019; Hyde and Atkinson, 2019).

This article focuses on the experiences of Welsh young people leaving care during COVID19 and considers the ways in which the pandemic has affected these already difficult and challenging pathways. Accordingly, the paper makes a contribution to both an established evidence base concerned with transitions to adulthood for care leavers, and an emerging literature concerned with understanding the impacts of the pandemic.

The paper begins by contextualising the experiences of care leavers within the wider literature on transitions to adulthood. This is followed with a summary of the emergent international literature in respect of the pandemic and the anticipated, or known, impact for young people leaving care. An overview of the study is presented before data from care leaver participants is introduced to highlight their concerns about to transitions to adulthood; namely the safety and security of their 'home', engagement in education and employment, maintenance of health and well-being and the availability of support. The findings highlight how the pandemic has amplified disadvantage for care experienced young people in Wales and made their transitions to adulthood a 'massive struggle'.

\section{Care leavers' transitions to adulthood}

There are debates about the extent to which pathways to adulthood have illustrated continuity or become more prolonged and complex (Brooks, 2007). The train track analogy represented linear trajectories between adolescence and adulthood, where young people, often bound by expectation and precedent, progressed from education into employment and from dependent living to independent living (Williamson 2004). In contrast, Arnett (2000) suggested a period of 'emerging adulthood', which affords individuals more choice and opportunity to experiment with their identity, relationships, and professions. However, Arnett's concept of 'emerging adulthood' as a new developmental stage between adolescence and adulthood has been criticised on the basis that it fails to acknowledge the 
diversity of young people's lives and the inequalities that some young people have to negotiate, particularly where their agency is fragile (Juvonen, 2014).

Rejecting notions of choice and experimentation, Cote and Brynner (2008) situate young people as 'floundering' in unstable employment. Economic instability and competitive labour markets mean that some young people face trajectories that are non-linear and reversible. These can be characterised by yo-yo transitions and a simultaneous engagement with youth and adult practices, with phases of independence and returns to dependence (Burnett 2010). Reflecting on the experiences of marginalised young adults, Green (2017: 155) argues that "their lives are increasingly constrained by disadvantage, discrimination and poor educational and occupational opportunities, whilst they are simultaneously presented with a myriad of limitless choices and opportunities many will never be able to access".

These accounts of instability in young people's lives have resonance for care leavers and the precarity of their lives (Berridge 2017; Wade et al 2011; Mannay et al 2017; Sebba et al 2015; Roberts et al. 2017; Roberts et al. 2019). However, transitions to adulthood are intensified for care experienced young people who are often required to manage multiple changes simultaneously, such as leaving education, leaving care, starting new education or employment, and living independently (Atkinson and Hyde, 2019). Additionally, for care experienced young people the "culture of parental dependence as a strategy...for coping with risks in a precarious environment' is often not an available or a viable option (Moreno, 2012: 19).

In a study of practice across 11 European countries, Stein (2019: 400) found that the majority of young people left care by 18 years of age and transitions were "more accelerated, compressed, and linear" with no opportunity to return to the care of corporate parents if initial decisions proved problematic. In Wales, the geographical focus of this paper, legislation provides that state support is available to care leavers up to the age of 21 , or 25 , for those in education or training (Welsh Government, 2018) and provisions such as the 'When I'm Ready' scheme ${ }^{1}$ seek to counter such disadvantage by supporting young people to remain with their foster carers post-18. Whilst these provisions may be considered welldeveloped by international standards, as noted by Strahl et al. (2020) concerns about disadvantage and inequality for care leavers remain consistent across diverse contexts.

Yet whilst transitions to adulthood are acknowledged to be particularly challenging for young people leaving care, it has been argued that the COVID-19 pandemic has amplified the precariousness of care leavers' positions and their access to support and services (Scottish 
Care Leavers Covenant Alliance, 2020). A survey of professionals ( $n=95)$ from 20 European countries suggested that care leavers faced additional challenges in respect of education, care and safety, mental health and wellbeing, isolation, participation, and involvement in decision making, exposure to violence and abuse, family life, income and employment, inaccessible services and securing basic essentials (Larkins et al, 2020). Evidence from both within and outside of the UK nations has also highlighted concerns in respect of loneliness, social and digital exclusion, mental health, food poverty, financial precarity, and childcare provision for care-experienced parents (Kelly et al., 2020; Lotan et al., 2020; NYAS, 2020; O'Higgins et al., 2020; McGhee and Roesch-Marsh, 2020; Staf, 2020).

\section{The Study}

In exploring the impact of COVID-19, this study sought to offer a platform for the voices of young people and provide opportunities for them to share their experiences of the pandemic. The data presented were generated as part of a study commissioned by [REMOVED FOR PEER REVIEW] to explore the experiences of young people who had left or were leaving state care during the COVID-19 pandemic. The study featured data generated with young people, which is the focus of this paper, and a survey with social care practitioners $(n=23)$ (see REMOVED FOR PEER REVIEW).

In total, 21 young people participated in the study, 17 were female and four were male. Interviews were conducted by the research team $(n=6)$ who had all previously worked with care experienced children and young people. The sample did not directly reflect the gender balance of the public care population in Wales, which in 2019 was closer to an equal gender distribution, 3,695 boys and 3,150 girls (Welsh Government, 2019). Two participants were aged $17(n=2)$ and the remainder were aged 18 to $24(n=19)$. Participants were living in areas of north, mid and south Wales $(n=17)$ and England $(n=4)^{2}$, the majority of participants resided in their own or in shared accommodation $(n=14)$, while others lived in hostel accommodation $(n=4)$ or post 18 placements $(n=2)$. One young person remained with foster carers $(n=1)$ and another was temporarily living with her partner's mother whilst awaiting more permanent accommodation $(n=1)$.

Ethical approval for this study was provided by [REMOVED FOR PEER REVIEW] and the study design considered the precarity and vulnerability of care experienced young people (Shaw and Holland, 2016; Bengtsson and Mølholt, 2016). Participants were purposively recruited via local authority and third sector organisations to ensure continued access to support. They were invited to contribute to the study via an individual interview $(n=17)$ or group interview $(n=3)$, and/or by sending in a written response $(n=1)$, poetry $(n=2)$, or artwork $(n=2)$. This multimodal approach drew on previous studies that had attempted to 
enable participants to take part in the research in a meaningful way that was led by their preferences (see Mannay et al., 2019; Smith, 2019).

The research commenced nine weeks into the first 'lockdown' in Wales, at a time when restrictions on business, travel and contact with other households were beginning to ease (see Senedd Research 2021). In accordance with Welsh Government restrictions at the time of data production (26 May - 14 July 2020), the research was conducted remotely. Communication took place over online platforms such as Zoom, email and phone, being mindful of the digital divide that impacts on the lives of many care-experienced young people (McGhee and Roesch-Marsh, 2020). Young people were given a gift voucher of £20 as an appreciation of their time participating in the study.

Interview and focus group data were transcribed verbatim and analysed concurrently throughout data production. Data were analysed using an inductive and deductive approach (Fereday, 2006) whereby interview transcripts were individually coded and themes generated from patterns emergent within and across the data. In addition, data was examined using a deductive approach, which involved considering participants responses through the lens of transitioning to adulthood. The visual materials and poetry submissions were also considered in the analysis to clarify and extend the associated themes generated in the interviews.

Following best practice models from previous studies (Staples et al., 2019), we consulted with the research advisory group [REMOVED FOR PEER REVIEW] during the study ${ }^{3}$. This included seeking young people's advice in the development of the research design and providing the group with an outline of the initial findings. The findings were validated by group members, who confirmed they resonated with their reflections as 'experts by experience' (Preston-Shoot, 2007). Discussions related to the research findings assisted in generating recommendations for policy and practice and members asked us to emphasise the importance of face-to-face support following the easing of restrictions and to highlight the need for clearer signposts alerting young people to sources of support within and outside of office hours.

\section{Findings}

\section{The significance of 'home' in the pandemic}

The increased need to stay at 'home' during the pandemic was a recurrent focus of the interviews. Young people's reflections varied depending on the extent to which home was imbued with feelings of safety, belonging, and stability. For young people happy at 'home', 
this had the potential to moderate some of the stresses of living through the pandemic. However, for young people in temporary or unsafe accommodation, being confined to 'home' amplified their anxieties.

Some young people discussed their home as a supportive and safe space. Cooking and watching films featured in activities for young people, especially for those with a co-habiting partner. Similarly, one young person reflected on new routines within her foster family where she supported efforts to entertain younger children. Despite these positive reflections about staying at home, the model scene below illuminates more unsettled feelings connected to the pandemic. The scene was created by a young person to depict the virus in their hometown, hovering above and casting a shadow over the deserted neighbourhood.

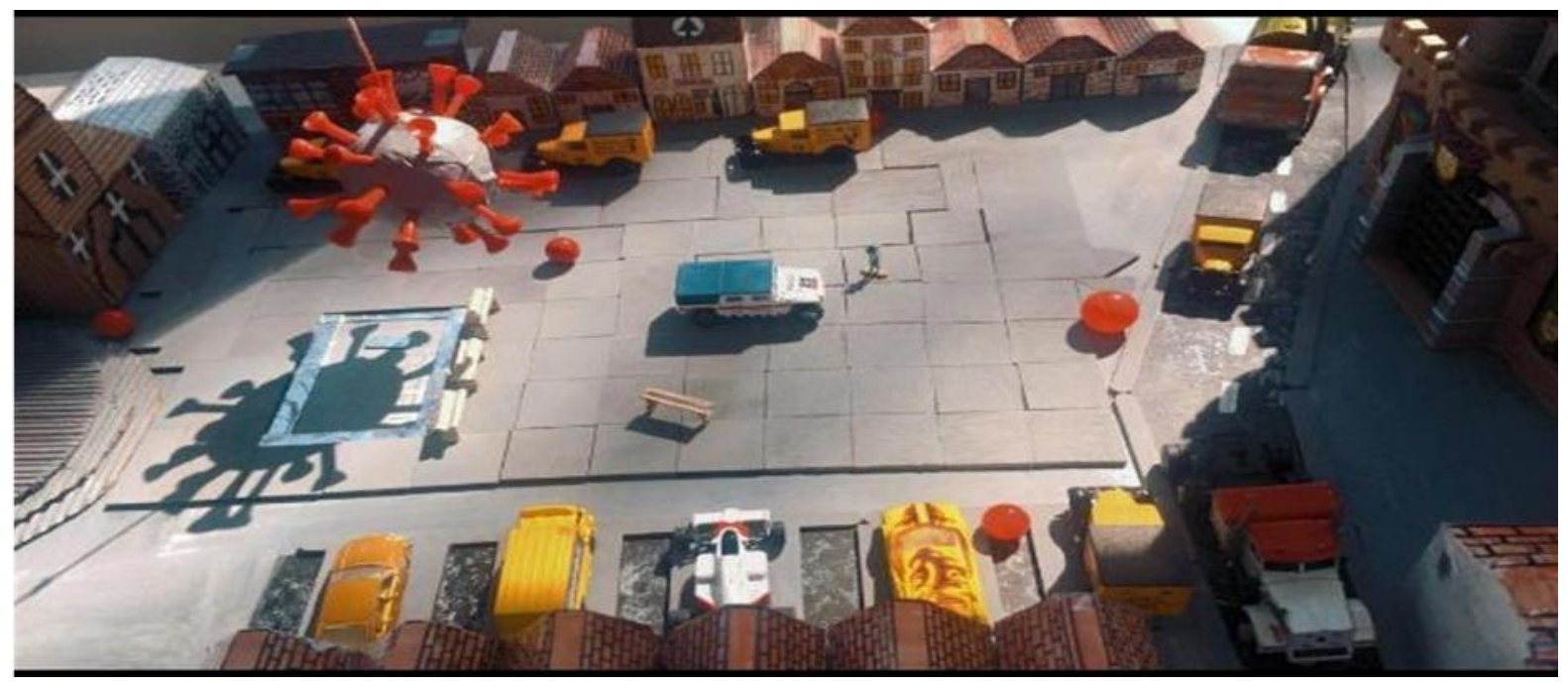

Figure 1: A young person's representation of COVID-19 in their locality

For those in stable accommodation, the shadow of uncertainty still had an effect but for those in more precarious accommodation, this shadow became all encompassing. The impacts of moving from place to place are a predominant feature in care experienced young peoples' lives (Cunningham and Diversi, 2012; Girling, 2019), and research by Baker at al., (2019) reported that only half of care leavers felt settled about where they lived. The Welsh Government (2020) has acknowledged the need to delay move-on arrangements, nonetheless, some participants experienced urgent accommodation needs and in the pandemic the consequences of housing instability were more keenly felt. For example, Tracy shared her challenging living situation.

Tracey: 'Got kicked out my foster carers in March. I stayed with one of my friends ... then the local authority of [name of local authority] me in [name of hotel] ... then went 
to live with my sister in [name of place] ... then found out that I got the flat, I then moved in I think it was four weeks ago'.

This form of instability is difficult to negotiate at any time, but in lockdown where it was advised that everyone should self-isolate and stay at home, this five-step series of moves to permanence was particularly difficult. The urgency to accommodate young people during the pandemic led to inappropriate placements such as bed and breakfast provision for Tracy. Amy similarly discussed being moved to an adult hostel at the start of the lockdown, which was populated by much older adults with a range of mental health issues and problems with addiction.

Amy: 'There are still a lot of people drinking in each other's rooms. There's also different types of illegal substances getting into the building, cos a couple of nights ago there was an incident where police got called cos three people claimed they had been spiked by a resident from an illegal substance... then there was another incident where [a female] was messaging me nasty things and stuff. It's got to the point where I am just in my room all the time.'

Arguably, the unsuitable nature of Amy's 'home' would be felt outside of the COVID-19 pandemic, however the lockdown restrictions limited Amy's ability to escape her surroundings and access support in dealing with these difficult situations.

Whilst shifts in the economy may have disrupted stable patterns of early adulthood for a wide demographic of young people (Brooks, 2007; Burnett, 2010; Cote and Brynner, 2008), stability was particularly problematic for the participants in this study. The option of yo-yo transitions that rely on the option of returning to the family home (Burnett, 2010) or the protective factors associated with delayed departures from the parental home (Moreno, 2012), discussed earlier in the paper, are often removed for care experienced young people who have experienced early separation from parents, siblings, and wider kinship support systems. Consequently, their transitions to adulthood are accompanied by additional layers of complexity and uncertainty (Atkinson and Hyde, 2019), to which the COVID-19 pandemic has added further change, flux, and insecurity. As such, constructions of an 'emerging adulthood' (Arnett, 2000), which afford individuals more choice, do not align well with the accounts of the young people who we worked with during the pandemic, whose precarious and potentially damaging 'homes' limited choices and undermined their wellbeing. The following section will move from the space of the home to consider young people's accounts of education and employment. 


\title{
Education and employment - uncertainty in the pandemic
}

The pandemic brought change and disruption to young people's education and employment. Positive engagement in education and employment had the potential to mitigate stresses and uncertainties. Nonetheless, for the majority of young people in this study, the pandemic created additional practical, financial, and health-related difficulties.

For young people in education, there were reports of disruption and abrupt endings. In some cases, courses finished prematurely, or educational provision moved online. Some participants discussed how being able to continue with their education provided a valuable focus during the pandemic. However, the challenging circumstances of the pandemic sometimes inhibited young people's ability to engage with study. For example, Bethan talked about the difficulties she faced in adapting to online learning.

\begin{abstract}
Bethan: 'Like I would not really know what to do. And that frustrated me quite a bit.......in the class we had like a support worker thing like she'd be there helping us if we needed it but obviously like when we're working from home she wasn't able to do that. And it just got a bit too difficult'.
\end{abstract}

Bethan's frustrations in respect of online learning may have been shared with many young people, regardless of care-experience. Yet such difficulties need to be considered in addition to the range of educational barriers already known to impact the care-experienced population (Emond, 2012; Mannay et al., 2015). These barriers include professionals having low expectations of care-experienced young people's educational potential, as well as inconsistency in access to support and resources. Such factors have the potential to be intensified during the pandemic and disparities in educational outcomes further widened (Equality and Human Rights Commission, 2020). Related to this, some young people in this study expressed anxieties about the impact of disruption and brusque endings on their futures. For example, Bev's degree course ended abruptly and any planning for the future was halted:

'It just makes me really nervous because I don't know what I'm doing. We didn't really wrap up uni, like we just, they told us that it was going to close, but it closed like a lot earlier than it was supposed to. Now we have got a degree but ... I guess we didn't ... like plan our future, or get any ideas, meet with anyone, we didn't get any of those opportunities.' 
With limited social capital (The Children's Society, 2020), young people's ability to compensate for missed opportunities or find alternative sources of support were and will continue to be constrained.

For young people in employment, reports were similarly characterised by anxiety and uncertainty. Some young people discussed managing losses in income as a result of being furloughed ${ }^{5}$ or having to take sick leave. For example, Paul was required to self-isolate as he experienced COVID-19 symptoms but lost income as a result.

Paul: 'So obviously that impacted a lot on paying my rent and stuff like that. So it's been a lot of stress then, stuck in on my own in a lot of debt. It's stressful. I'm still in debt now. I got statutory sick pay, but my rent costs more than what I get for sick pay so it doesn't really help.'

In another example, Tracy was pregnant and as a carer, was especially anxious about the risk of contracting COVID-19. Tracy described multiple and competing demands as she wanted to prioritise the health and development of her unborn child, yet simultaneously felt under pressure to ensure sufficient income to prepare for her baby. Such dilemmas were further compounded by her having no access to company sick pay as an agency worker, as well as a reduction in work opportunities.

Tracy: 'With the virus, they don't really want agency workers, they want permanent staff so we are not moving from one home to another and possibly spreading it'.

As noted earlier, Green (2017) has questioned the extent to which discourses of young adulthood being defined by limitless choices can marry with the realities of poor educational and occupational opportunities. For care experienced young people this alignment is further weakened, and the accounts of Paul and Tracy exemplify an additional barrier relating to the disproportionate impact of COVID-19. As argued by Blundell et al. (2020, pp. 292) the pandemic does not impact on individuals in the same way and 'the most vulnerable groups by socio-economic background and health status are also those that may be hit the hardest". Analysis by the Equality and Human Rights Commission (2020) anticipates young people are particularly at risk of increased poverty and hardship as a result of reduced employment opportunities and losses of income. For care-experienced young people in low paid and insecure employment, the pandemic has the potential for catastrophic consequences, with young people facing choices between prioritising health (their own and others) or being able 
to sustain the costs of daily living. Viewed in this way, the support young people have access to during these challenging times is likely to be crucial, and sources of support will be further explored in the following section.

\section{Young People and 'remote support' in the pandemic}

The pandemic prompted a shift in routine support, with a move from face-to-face to telephone or online contact. Young people reflected on their changed access to professional support, highlighting benefits, challenges and considerations for future practice. Friendship can act as a protective factor for care experienced young people (Ulset, 2016); yet the lack of access to friends and loved ones, combined with lost routines of education and employment, had the potential to be a 'doubly isolating experience' for care leavers, who may already have been suffering from loneliness and disconnection (Mike S, 2020). Consequently, contact from social workers and personal advisors became even more important to some young people during the COVID-19 pandemic. This shift was explained in a poem written by one of the participants.

Times have changed, time is passing,

But our need for you to care is not lapsing,

We may whinge and shout and say we don't want,

But we do, we really want you to.

We are isolated, changed and really not sure,

We need that face, the one we say we dislike,

We need those texts that we never reply to,

We need the language that you share, they hey,

'How are you doing, I am still here',

This is the real language that cares, the language we need,

The language which shows us not everything has changed,

The language that comforts us, like a weird aunt would send

Which would make us cringe, and smile,

A smile which means something hasn't changed 
The language you use to show us you care.

The poem highlighted how the need for contact was accentuated by the COVID-19 pandemic, as it reflected on how isolation, change and uncertainty shifted the relationship with, and expectations of social services. Prior to the pandemic, contact from social services may have been regarded as unnecessary 'we don't want', or undesirable 'dislike' and 'never reply'. However, with this unsettling change in circumstances, there was a 'need' for contact, communication, reassurance and 'comfort', and a desire for a 'language that cares'. As noted in the poem, this could be face-to-face, or remote. The usefulness of remote contact was noted by Ceri, who experienced lockdown in her student residence.

Ceri: 'My PA [personal advisor] should come to see me every six weeks. But in my whole university time, she only came up once ... She can just call me for half an hour and talk to me instead of all the travelling ... We probably message more now than we did prior to the lockdown ... It's good, and I hope it continues that way after the lockdown has been lifted ... hopefully after lockdown has been lifted, phone calls or video calls will not be pushed aside [laughs] because I think they are great [laughs].'

Later in her interview, when reflecting on her care experienced sibling, and the less positive relationship between her sibling and their personal advisor, Ceri discussed the importance of these calls and how these contacts could be essential for some young people in the lockdown period.

Ceri: And, you may not think that it means much, like a lot, but it does. For somebody, especially in lockdown when you think that you're all alone, and to have a message saying 'how are you doing' or 'just wanted to check up on you' or something, it gives you a boost of confidence to know that there are people out there that are willing to help you if you are struggling.

Ceri's comments are consistent with pre-pandemic findings highlighting the importance for young people of being supported by caring and invested professionals (Brown et al. 2019; Rogers 2011). Ceri's report of increased frequency in her contact with her personal advisor also support the findings of the professional survey connected to this study (see REMOVED FOR PEER REVIEW), which noted remote communication methods have the potential to be more efficient, enabling more frequent and meaningful contact. 
Nonetheless, criticisms of remote contact were also reported, including the potential for insensitive contact which illuminated material inequalities. For example, Mary discussed how the background on her social worker's video call acted as a semiotic visual signifier of the inequalities in their different living arrangements.

'Yeah and I got a video call from one of the social workers and she was in her nice house, in the garden in a summer top, and I'm stuck here in the flat. I just think consider going inside in your bedroom... And things like that just make you feel shit so you get off the phone and you are left in a shit flat, thinking well they've got a nice home'.

Furthermore, while the need for remote contact was often accepted as necessary in the pandemic, the importance of face-to-face contact was also repeatedly highlighted. Many young people reflected on the significance of in-person contact and felt that virtual contact should not come to replace face-to-face visits after the pandemic.

While many young people discussed positive, and less positive, communications with social workers, personal advisors, and advocates from charity organisations, it is important to note that not all young people experienced increased remote support. As discussed in the earlier account from Jemma, some felt deserted and reported increased difficulties in accessing support because of remote working. For example, Paul reported receiving no support during the pandemic:

'I have tried ringing everyone in the office, but I still can't get hold of my social worker to this day. I haven't spoken to him in 5 - 6 months'.

Paul's comments stand in contrast to policy commitments prior to and during the pandemic to maintain support to young people post-18 (Welsh Government 2018; Welsh Government 2020). This highlights the importance of pro-active and regular professional contact when adopting remote contact methods. In contrast to notions of 'independence', young people were increasingly reliant on professionals initiating contact as they had lost the ability to seek support through a call or visit to their local office. This positioning aligns with conceptualisations of adulthood that recognise phases of independence and returns to dependence (Burnett 2010); but not those which centralise increased choice and autonomy as key feature of young adulthood (Arnett, 2000). 
Young people emphasised the importance of professional support during the COVID-19 pandemic and the potential for relationships to be maintained, if not strengthened, despite the challenging circumstances (Pitt 2020). Yet their comments also highlighted the potential for relationships to be damaged or neglected. This theme will be explored further in the following section.

\section{Young People, parenthood and 'surveillance' in the pandemic}

For young people who were pregnant or parenting, the pandemic created additional concerns related to the health, well-being, and the care of children. Pregnancy and parenthood had the potential to exacerbate young people's stresses in relation to housing, support, and the availability of resources. Yet the ways in which young people described responses to their needs from corporate parents were more typically characterised by monitoring and surveillance, as opposed to meaningful help to negotiate the conditions of the pandemic.

Parenthood is a 'complex transition process that young adults have to pass through and have to manage' (Du Bois-Reymond, 2009: 265); and young people who become parents are often impacted by discourses of stigma and blame, and higher forms of surveillance of their parenting practices (Brady and Brown, 2013; Mannay et al. 2018a). For care experienced young people that become parents these forms of judgement and surveillance are even more significant (Roberts, 2017; 2019). For example, Paula described multiple challenges caring for her daughter in the pandemic, including financial concerns, being confined to a home with in a state of disrepair, accessing basic supplies whilst being a sole carer, and being required by social workers to limit contact with her child's father. Yet rather than responding to her heightened support needs, Paula stated the "support available from the system is basically non-existent as usual".

Consistent with Paula's comments, Julie stated:

I might as well have no fucking support off them... d'you know what I mean? The most support I need is money, that's what I need, people say 'what's money, you don't need money', that's the only support I need, for someone to help me.

Julie felt that on the one hand the basic resources she was requesting were difficult to negotiate, while on the other hand social services were keen to class her as vulnerable. 
Julie: Then they start telling me that I can't cope... So I'm thinking well the one minute you're saying you can't help me and the next minute you're saying I can't cope with anything.

For Julie, her positioning as 'vulnerable' was directly related to and made worse by the COVID-19 pandemic. However, rather than providing her with the financial support she needed, Julie felt that the label of 'vulnerable' was attached as a way for social services to infantilise and monitor her; and to increase their mechanisms of surveillance to a point where she 'wouldn't be able to do anything without informing them'. Julie's concerns about this heightened surveillance and the associated threats of her own child being taken into care had a significant impact on her experiences during the lockdown period. As well as going without adequate essential resources, Julie was reluctant to get help with her mental health issues as she felt that this would be reported, as a previous appointment with her doctor for issues with anxiety had been passed to social services. Consequently, for Julie asking for help during the pandemic was met with both a lack of practical and emotional support, and the threat of increased surveillance ${ }^{6}$.

Motherhood can be positioned as a source of pride and respect, marking an important transition to adulthood (Gillies, 2007). However, this pride and respect can become contaminated by discourses of stigma often attached to young parents (Mannay et al, 2018a), parents living in poverty (Tyler, 2008), and care experienced parents (Roberts, 2017; Morriss, 2018). These accounts raise questions about the extent to which markers of adulthood, such as parenthood, become overridden by conceptualisations of the care child and its associated stigmas; and the ways in which the COVID-19 pandemic may have accentuated ideas of vulnerability that further undermine the status of adulthood for care leavers who are parents.

\section{Young People and mental health in the pandemic}

The issue of mental health, as highlighted in Julie's account, is particularly concerning as care experienced young people are more likely to have issues with mental health (Smith, 2017) and $23 \%$ of care leavers have reported low wellbeing (Baker et al., 2019). Mental health in the UK in the general population has deteriorated compared with pre-COVID-19 trends (Pierce et al., 2020), and the negative impact of COVID-19 on care experienced young people's wellbeing has been recognised in recent studies (Staf, 2020; NYAS, 2020). Therefore, it is unsurprising that many young people who participated in this study raised issues around mental health and wellbeing. 
Holly: 'I haven't been leaving my bedroom... because I have been like, really bad in my depression. So, I haven't really been leaving my bedroom.... I think today is the first day I left which is quite good, it's a big step for me'.

Charlie: 'It's been hard. I suffer with mental health and going to work, going to the gym, seeing friends, helps with mental health. Because obviously during lockdown I can't work, I can't go to the gym, I can't see as many friends as l'd like to. The whole experience has been weird. It's been a massive struggle'.

Tom: 'I suffer from serious mental health, I suffer from ADHD and suffer from autism... and when they start kicking in, they, it, I start getting worked up... the first few weeks, once it had been a month I was like, this is getting boring. This is really boring now. It's ridiculous. And I was like getting all stressed, like I can't do this anymore, I can't do this, I hate being, I hate not being, going places'.

Jane: 'Absolute nightmare, that's one way of putting it. An absolute nightmare, that's the only way to put it... its good for my mental health to be out and doing something every day. But obviously, I can't get out now much'.

These comments are indicative of those across the data set where young people lamented the loss of previous routines and contact with others (see REMOVED FOR PEER REVIEW). For many young people, the losses coupled with extended periods of confinement in their homes resulted in their mental health difficulties becoming more pronounced. It has been previously reported that there is 'significant unmet need amongst care leavers who require mental health support' (Smith, 2017) and diminished mental health services during the COVID-19 pandemic likely accentuated their already precarious position. Supportive relationships are created and sustained through a number of mundane, yet important practices such as eating together and preparing food (Rees, 2019), being part of organised sport and arts activities (Gilligan, 1999; Mannay et al., 2021), and being able to stay in contact with peers via social media (Hammond et al., 2018). However, we can see from these accounts how being isolated closes down opportunities for socialising and going to the 'gym' or 'work'; and given the digital divide for care experienced young people (McGhee and Roesch-Marsh, 2020), even remote forms of online contact were not always accessible as a mechanism to combat the physical isolation of lockdown.

\section{Conclusion}

The accounts that young people chose to share with us in this study align with the established evidence base regarding difficult and disadvantaged transitions to adulthood for 
individuals who are care experienced. Unfortunately, challenges and inequalities in relation to health and well-being, housing, parenting, access to informal and formal support, education and employment are not unique to the COVID-19 pandemic. Nevertheless, the study has illustrated the ways in which the pandemic is making already difficult transitions to adulthood, 'a massive struggle' and 'a constant battle'.

The accounts of the young people we spoke to were not illustrative of the choice and opportunity associated with the period of 'emerging adulthood' (Arnett 2000). They did highlight aspects of prolonged and complex journeys (Brooks, 2007) phases of independence and returns to dependence (Burnett 2010), and disadvantage (Green 2017). However, while these may be experiences shared by many young people who are transitioning to adulthood, particularly during the COVID-19 pandemic, for individuals in and leaving care arguably these challenges are accentuated and at the same time the necessary resources for security and support are fewer and more difficult to access.

Whilst working practices under Covid-19 had provided some surprising but welcome opportunities for increased and meaningful contact with supporting professionals, in too many instances the young people in our study faced increased challenges in their transitions to adulthood, compounded by diminished service availability and individual ability to influence their situations. Of particular concern were the themes presented here in relation to access to basic provisions, being able to sustain the costs of daily living, residing in inappropriate accommodation, and struggling with the absence of both practical and emotional support. Such findings highlight the potential for young people's needs to be unmet in unprecedented and highly challenging circumstances. However, the findings also prompt consideration of the longer-term impact of COVID-19; for example, with deteriorations in mental health and well-being, and increased barriers to education and employment having the potential to further entrench and exacerbate existing disparity and inequality.

This study has provided an opportunity for young people to voice their concerns, but it is also important to consider the question, 'what impact does voice have if no one is listening?' (Alexandra, 2015: 43). As such, the research team have worked with care experienced young people in the [REMOVED FOR PEER REVIEW] research advisory group to clarify recommendations which promote positive transitions and parity of support (see REMOVED FOR PEER REVIEW). The report has been shared with policy makers, practitioners, and a range of other key stakeholders. Additionally, to move 'beyond the academic article' (Mannay, 2019: 659) the data produced with young people has been promoted with a blog, 
via social media and in a short film, in an attempt to increase accessibility, engagement and impact.

As the COVID-19 pandemic continues to cast a shadow over the lives of care experienced young people it is important to acknowledge that this has 'been a massive struggle'. It is imperative that corporate parents commit to increased resources to sustain 'their' children leaving care, to ensure the provision of appropriate accommodation which feels like 'home' and provide responsive mental health services, so that young people feel valued and supported. It should be the legislative right of young people to access leaving care services so they cannot be withdrawn in a crisis. For young people who have left care during COVID19 immediate funding is required to ward against further cumulative disadvantage in the longer-term. This paper has evidenced the problematic nature of transitions to adulthood for care experienced young people and emphasised the need for effective support for young who people left care during the COVID-19 pandemic.

\section{Endnotes}

1. The 'When I'm Ready' scheme was created by the Welsh Government in 2015 for young people to stay in their foster placements beyond the age of 18 and up until the age of 25 if they are involved in a programme of education or training.

2. Although the study was mainly focussed on young people in Wales, the research team were contacted by a Local Authority in England who requested opportunity for young people in their area to participate. As a result, four young people engaged in interviews and / or submitting poems or artwork.

3. REMOVED FOR PEER REVIEW

4. The first lockdown in Wales began on 23rd March 2020.

5. 'Furlough' refers to a UK job retention initiative whereby employees placed on leave during the COVID-19 pandemic were paid $80 \%$ of their wages by the Government.

6. Given the significant issues raised by this participant there were follow up telephone calls after the interview, the participant was put in touch with relevant support services and their advocate from a charitable organisation, who they had established a good relationship with, was also contacted with an update with the participant's permission. 


\section{References}

Alexandra, D. (2015). Are we listening yet? Participatory knowledge production through media practice: encounters of political listening. In A. Gubrium, K. Harper and M. Otanez (Eds), Participatory Visual and Digital Research in Action (pp. 41-56). Walnut Creek, CA: Left Coast Press.

Allnatt, G. (2019). Transitions from care to higher education: A case study of a young person's journey. In D. Mannay, A. Rees, and Roberts, L. (Eds) Children and young people 'looked after'? Education, intervention and the everyday culture of care in Wales (pp. 69-82). Cardiff: University of Wales Press.

Arnett, J. 2000. Emerging adulthood: A theory of development from the late teens through the twenties'. American Psychologist 50(5) 469-80

Artamonovaa, A., das Dores Guerreirob, M. and Höjer, I. (2020). Time and context shaping the transition from out-of-home care to adulthood in Portugal. Children and Youth Services Review 115, 105105.

Atkinson, C. and Hyde, R. (2019) Care leavers' views about transition: a literature review. Journal of Children's Services 14 (1) 42-58.

Baker, C., Briheim-Crookall, L., Magnus, L. and Selwyn, J. (2019). Our lives beyond care: care leavers' views on their well-being in 2018. London: Coram Voice. Retrieved 20 November 2020 from https://coramvoice.org.uk/wp-content/uploads/2019/09/OLBCSnapshot-online-2018.pdf

Bengtsson, T. T. and Mølholt, A. 2016. Keeping you close at a distance: ethical challenges when following young people in vulnerable life situations. YOUNG, 24(4) 359-375.

Berridge, D. (2017). The education of children in care: Agency and resilience. Children and Youth Services Review, 77, 86-93. https://doi.org/10.1016/j.childyouth.2017.04.004

Brady, E. and Gilligan, R. (2019). Exploring diversity in the educational pathways of careexperienced adults: Findings from a life course study of education and care. Children and Youth Services Review, https://doi.org/10.1016/j.childyouth.2019.06.014

Brady, G. and Brown, G. (2013). Rewarding but let's talk about the challenges: using artsbased methods in research with young mothers. Methodological Innovations Online, 8(1), 99-112. 
Brooks R. (2007). Transitions from education to work in the twenty-first century. International Journal of Lifelong Education (Special issue: Transitions from Education to Work), 26 (5), 491-493.

Burnett, J. (2010). Contemporary adulthood: calendars, cartographies and constructions. London: Palgrave Macmillan.

Côté, J. and Bynner, J. M. (2008) 'Changes in the transition to adulthood in the UK and Canada: The Role of Structure and Agency in Emerging Adulthood', Journal of Youth Studies 11(3): 251-68.Blundell, R., Costa Dias, M., Joyce, R. and Xu, X. (2020). COVID-19 and Inequalities. Fiscal Studies, 41: 291-319.

Craine, N., Midgley, C., Zou, L., Evans, H., Whitaker, R. and Lyons, M. (2014). Elevated teenage conception risk amongst Looked After Children: a national audit. Public Health, 128(7), 668-70.

Cunningham, M.J. and Diversi, M. (2012). Aging out: Youths' perspectives on foster care and the transition to independence. Qualitative Social Work, 12(5): 587-602.

Du Bois-Reymond, M. (2009) Young parenthood in the Netherlands. YOUNG, 17 (3): 265283.

Emond, R. (2014). Longing to belong: Children in residential care and their experiences of peer relationships at school and in the children's home. Child \& Family Social Work, 19 (2): 194-202.

Equality and Human Rights Commission (2020) How coronavirus has affected equality and human rights. Retrieved 26 November 2020 from

https://www.equalityhumanrights.com/sites/default/files/equality and human rights commis sion how coronavirus has affected equality and human rights 2020.pdf

Fereday, J. (2006). Demonstrating Rigor Using Thematic Analysis: A Hybrid Approach of Inductive and Deductive Coding and Theme Development. International Journal of Qualitative Methods, 5(1), 80-92.

Gillies, V. (2007). Marginalised mothers: Exploring working class parenting. Abingdon: Routledge.

Gilligan, R. (1999). Enhancing the resilience of children and young people in public care by mentoring their talents and interests. Children and Family Social Work, 4, 187-196.

Girling, R. (2019). Yet another change: The experience of movement for children and young people looked after. In D. Mannay, A. Rees, and L. Roberts, (Eds), Children and young 
people 'looked after'? Education, intervention and the everyday culture of care in Wales (pp. 127-139). Cardiff: University of Wales Press.

Green, L. 2017. Understanding the Life Course. 2nd ed. Polity Press: Cambridge

Hammond, S. P., Cooper, N. and Jordan, P. (2018). Social media, social capital and adolescents living in state care: A multi-perspective and multimethod qualitative study. British Journal of Social Work, 48(7), 2058-2076.

Juvonen, T, 2014. Fragile agencies in the making: challenges of independent living in emerging adulthood. YOUNG, 22(3) 253-269.

Kelly, B., Walsh, C. Pinkerton, J. and Toal, A. 2020. The Voices of Young People Leaving Care During Covid-19 in Northern Ireland. [online] Available at: https://www.voypic.org/wpcontent/uploads/2021/01/Leaving-Care-During-Covid-19-in-NI-FINAL-REPORT.pdf Accessed 2.2.21

Larkins, C. et al. 2020. COVID-19: Children's Participation in shaping responses. Available at:

https://www.eurochild.org/fileadmin/public/04_News/Eurochild/Child_Participation_in_COVID -19_Respone_Rapid_Paper.pdf [Accessed 11 September 2020]

Lotan, H. et al. 2020. Care leavers versus at-risk youth in the community during Covid-19 outbreak in Israel. Available at:

https://drive.google.com/file/d/19lckCDTY7lv01CEPVVzZLLQAmm1J3yPd/view [Accessed: 21 July 2020]

Mannay, D., Staples, E., Hallett, S., Roberts, L., Rees, A., Evans, R. and Andrews, D. (2015). Understanding the educational experiences and opinions, attainment, achievement and aspirations of looked after children in Wales. Cardiff: Welsh Government.

Mannay, D., Staples, E., Hallett, S., Roberts, L., Rees, A., Evans, R. and Andrews, D. (2017). The consequences of being labelled 'looked-after': Exploring the educational experiences of looked-after children and young people in Wales. British Educational Research Journal 43(4), 683-699.

Mannay, D., Creaghan, J., Galleghar, D., Mason, S., Morgan, M. and Grant, A. (2018a). 'Watching what l'm doing, watching how l'm doing it': Exploring the everyday experiences of surveillance and silenced voices among marginalised mothers in Welsh low-income locales. 
In T. Taylor, and K. Bloch, (Eds), Marginalized Mothers, Mothering from the Margins. Advances in Gender Research (Vol. 25). Bingley: Emerald.

Mannay, D., Smith, P., Turney, C., Jennings, S. and Davies, P. 2021. 'Becoming more confident in being themselves': the value of cultural and creative engagement for young people in foster care. Qualitative Social Work https://doi.org/10.1177/14733250211009965

Mannay, D., Staples, E., Hallett, S., Roberts, L., Rees, A., Evans, R., and Andrews, D. (2019). Enabling talk and reframing messages: working creatively with care experienced children and young people to recount and re-represent their everyday experiences. Child Care in Practice 25(1), 51-63.

Mannay, D. (2019). Revisualizing data: engagement, impact and multimodal dissemination. In L. Pauwels and D. Mannay, (Eds), The Sage Handbook of Visual Research Methods (2nd Edition) (pp 659-669). London: SAGE Publications.

McGhee, K. and Roesch-Marsh, A. (2020). Bridging the digital divide for care experienced young people in Scotland: If not now, when? Retrieved 20 November from:

https://www.celcis.org/knowledge-bank/search-bank/bridging-digital-divide-careexperienced-young-people-scotland-if-not-nowwhen/\#: :text=not\%20now\%2C\%20when\%3FBridging\%20the\%20digital\%20divide\%20for\%20care\%20experienced\%20young\%20people \%3A\%20lf\%20not\%20now\%2C\%20when\%3F\&text=This\%20report\%20has\%20been\%20pr oduced,responded\%20to\%20these\%20specific\%20needs.

Mike S. (2020). Clap for care leavers and those with care experience. Social Work 2020 under COVID-19 Magazine, 4th Edition June 2nd, 2020. Retrieved 20 November from: https://sw2020covid19.group.shef.ac.uk/category/fourth-edition/

Moreno, A. (2012) The transition to adulthood in Spain in a comparative perspective: the incidence of structural factors. YOUNG, 20(1): 19-48

Morriss, L. (2018) Haunted futures: The stigma of being a mother living apart from her child(ren) as a result of state-ordered court removal. The Sociological Review, 66(4): 816831.

NYAS. (2020). Young lives in lockdown: NYAS' survey of care-experienced children and young people during COVID-19. Retrieved 20 November from: https://www.nyas.net/wpcontent/uploads/NYAS-Coronavirus-Survey-Report-Young-Lives-in-Lockdown-May-2020.pdf O'Higgins, A, Canning, R. and Taylor, J. 2020. Care in the Time of Covid: Summary. [online] Available from: https://careinthetimeofcovid.org/ Accessed 2.2.21 
Pierce, M. et al. (2020). Mental health before and during the COVID-19 pandemic: a longitudinal probability sample survey of the UK population. Retrieved 20 November from: https://www.thelancet.com/journals/lanpsy/article/PIIS2215-0366(20)30308-4/fulltext

Pitt, C. (2020). Working better together: How do we build stronger relationships between social workers and people using services? Social Work 2020 under COVID-19 Magazine, 5th Edition July 14th, 2020 Retrieved 20 November from:

https://sw2020covid19.group.shef.ac.uk/category/5th-edition-july-14th-2020/

Preston-Shoot, M. (2007). Whose Lives and Whose Learning? Whose Narratives and Whose Writing? Taking the Next Research and Literature Steps with Experts by Experience', Evidence \& Policy: A Journal of Research, Debate and Practice, 3(3), 343-59.

Rees, A. (2019). The daily lived experience of foster care. In D. Mannay, A. Rees, and L. Roberts, (Eds), Children and young people 'looked after'? Education, intervention and the everyday culture of care in Wales (pp. 85-99). Cardiff: University of Wales Press.

Roberts, L. (2017). A small-scale qualitative scoping study into the experiences of looked after children and care leavers who are parents in Wales. Child \& Family Social Work, 22(3), 1274-1282.

Roberts, L. (2019). 'A family of my own': When young people in and leaving state care become parents in Wales. In D. Mannay, A. Rees, and L. Roberts, (Eds), Children and young people 'looked after'? Education, intervention and the everyday culture of care in Wales (pp. 140-152). Cardiff: University of Wales Press.

\section{REMOVED FOR PEER REVIEW}

Scottish Care Leavers Covenant Alliance (2020). The challenge of 2020: Supporting care leavers in Scotland during the pandemic and beyond. Retrieved 11 September from https://www.celcis.org/knowledge-bank/search-bank/scottish-care-leavers-covenant-alliancecollaborative-voice-briefing/

Sebba,J., Berridge , D., Luke, N., Fletcher, J., Bell, K., Strand, S., Thomas, S., Sinclair, I and O'Higgins, A. (2015) The Educational Progress of Looked After Children in England: Linking Care and Educational Data, Oxford: Rees Centre for Research in Fostering and Education and University of Bristol.

Senedd Research (2021). Coronavirus timeline: Welsh and UK Government's Response. Retrieved $5^{\text {th }}$ May from: https://research.senedd.wales/media/kzze54jv/coronavirus-timeline290321.pdf 
Shaw, I. and Holland, S. (2014). Doing qualitative research in social work. London: Sage.

Smith, N. (2017). Neglected Minds: a report on mental health support for young people leaving care. Ilford: Barnardo's.

Smith, P. (2019). A view from a Pupil Referral Unit: Using participatory methods with young people in an education setting. In D. Mannay, A. Rees, and L. Roberts, (Eds), Children and young people 'looked after'? Education, intervention and the everyday culture of care in Wales (pp. 183-195). Cardiff: University of Wales Press.

Social Services Improvement Agency (SSIA). (2016). Social Services Improvement Agency: Corporate Parenting Workbook. Retrieved 11 September from https://socialcare.wales/cms assets/file-uploads/9a-Corporate-Parenting-Workbook.pdf Staf. (2020). Staf report: COVID-19 impact on care leavers highlights need to build back better. Retrieved 11 September from

https://www.staf.scot/Handlers/Download.ashx?IDMF=9822be5f-8855-4e7d-be08$\underline{\mathrm{ab} 380962 \mathrm{f} 4 \mathrm{ab}}$

Staples, E., Roberts, L., Lyttleton-Smith, J. and Hallett, S. (2019). Enabling care-experienced young people's participation in research: CASCADE Voices. In D. Mannay, A. Rees, and L. Roberts, (Eds), Children and young people 'looked after'? Education, intervention and the everyday culture of care in Wales (pp. 196-209). Cardiff: University of Wales Press.

Stein, M. (2012) Young People Leaving Care: Supporting Pathways to Adulthood. London: Jessica Kingsley

Stein, M. (2019) Supporting young people from care to adulthood: International practice. Child \& Family Social Work 24: 400- 405. https://doi.org/10.1111/cfs.12473

Strahl, B., Van Breda, A., Mann-Feder, V. and Schröer, W. (2020). A multinational comparison of care-leaving policy and legislation. Journal of International and Comparative Social Policy, 1-16.

The Children's Society. (2020). The impact of COVID-19 on care leavers. Retrieved 11 September from https://www.childrenssociety.org.uk/sites/default/files/cv-19-impact-on-careleavers 3.pdf

Tyler, I. (2008). Chav mum chav scum. Feminist Media Studies, 8(1), 17-34.

Ulset, G. (2016). Vennskap - perspektiver og tilnærminger blant ungdom i barneverninstitusjon. Tidsskriftet Norges Barnevern, 93 (2). 
Wade, J., Biehal, N., Farrelly, N. and Sinclair, I. (2011) Caring for Abused and Neglected Children: Making the Right Decisions for Reunification or Long-Term Care, London: Jessica Kingsley.

Welsh Government (2018) Social Services and Well-being (Wales) Act 2014: Part 6 Code of Practice (Looked after and Accommodated Children). Retrieved 11 September from https://gweddill.gov.wales/docs/dhss/publications/180328pt6en.pdf

Welsh Government (2019). Children looked after at 31 March by local authorities, gender and age. Cardiff, Welsh Government. Retrieved 11 September from https://statswales.gov.wales/Catalogue/Health-and-Social-Care/Social-Services/ChildrensServices/Children-Looked-After/childrenlookedafterat31march-by-localauthority-gender-age Welsh Government. (2020). Children's social services during the COVID-19 pandemic: guidance. Retrieved 11 September from https://gov.wales/childrens-social-services-duringCOVID-19pandemic-guidance-html

Williamson, H. (2004). The Milltown boys revisited. Oxford: Berg. 